\title{
Haulage Mode-Choice of Chinese Railway Traffic by the Analytic Hierarchy Process
}

Xiaoquan Gong

Institute of Management Science

Northern Jiaotong University, Beijing, P.R. of China

\section{Abstract}

This paper recounts the step-by-step procedures for synthetic estimation of haulage modes of Chinese railway traffic by using the Analytic Hierarchy Process (AHP), and puts forward certain constructive suggestions for making three kinds of main haulage modes yield well.

\section{Introduction}

Railway traffic is one of the most important components of Chinese national economy. At present, the traffic capacity of railway traffic cannot fit in with the rapid increase in passenger and freight traffic volume. Overstocking and overloading are common phenomena now. Railway traffic has become the weak Iink constraining the development of the Chinese economy. In order to enlarge traffic performance and compete with other traffic modes (highway traffic, shipping, aviation transport and pipe transportation) it is essential to draw lessons from other countries and quicken the pace of railway's modernization so as to extend haulage capacity of locomotives, which is the key means to have the aim of railway's modernization come true.

Steam locomotives once were the primary haulage mode of Chinese railway traffic. Now, electric and diesel locomotives are also undertaking traffic volume partly. Electric and diesel locomotives have the obvious advantage in traffic capacity over steam locomotives. It is undoubted that replacing steam locomotives by electric and diesel locomotives is a root means to 
solve the contradiction between traffic capacity and traffic volume. But the electrification and dieselization of railway need large quantities of investment expenditure. China is a developing country, national financial resources are limited, and it needs plenty of time and investment for the locomotive's manufacturing and repairing departments to change productive framework so as to meet the demand of electric and diesel locomotives, so railway's moderrization cannot be accomplished at one stroke.

Many experts are inquiring about how to make the best of three main kinds of haulage modes mentioned above. The first main point of their research is: which of electric or diesel traction should play leading role, the second is concentrating on dispute of whether to eliminate the steam locomotives or not, and up to now no unanimous conclusions have been reached as opinions vary in china.

Saaty's Analytic Hierarchy Process. renders an approach to multicriteria problem solving. In this paper we develop-the stepby-step procedures for the mode-choice analysis of china's railway traffic by using the AHP.

\section{Hierarchy structure}

First the hierarchy is structured to obtain the basic element of this problem. In the first stage we worked downward from the destination in the top. level to the criteria in the second level. Each criterion bearing on the destination can be broken down into subcriteria in the third level, and the bottom level of the hierarchy contains the modes to be chosen. The hierarchy. 

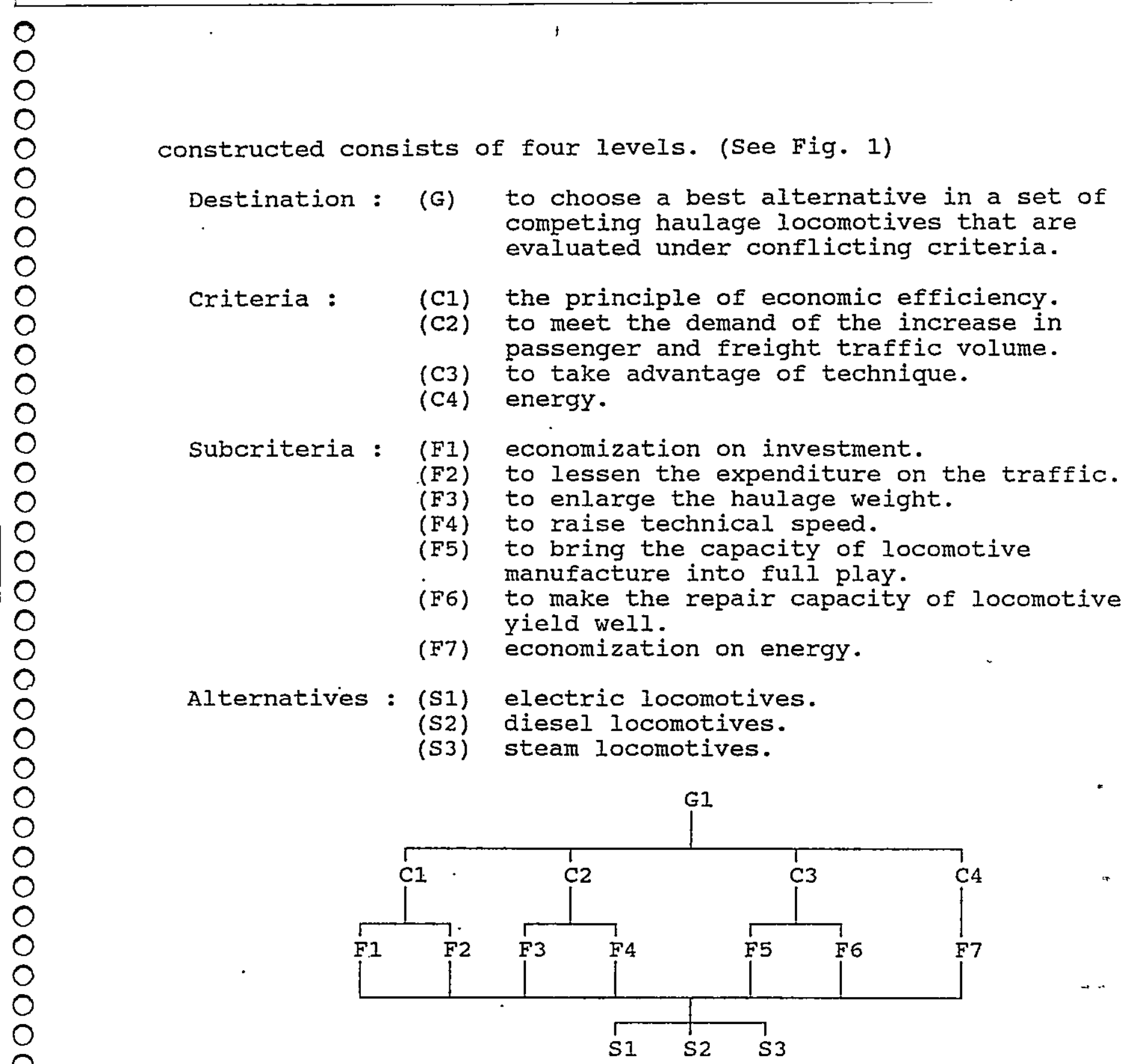

Figure 1. The proposed hierarchy structure

\section{Setting up Comparison Matrices and Verifying Consistency}

Now matrices can be set up to accomplish pairwise comparison of relative importance of elements in current levels with respect to the appropriate elements in the higher levels. The scale for entering judgments is given in Table 1 , thus, a series of square matrices of ratios may be formed which have positive elements 
$[a(i, j)>0]$, are reciprocal $[a(i, j)=1 / a(j, i)]$, and have unity as their diagonal elements $[a(i, i)=1]$.

$$
A=\left[\begin{array}{cccc}
a(1,1) & a(1,2) & \ldots & a(1, n) \\
a(2,1) & a(2,2) & \ldots & a(2, n) \\
a(n, 1) & a(n, 2) & \cdots & a(n, n)
\end{array}\right]
$$

Table 1. The AHP Scale for Paired Comparisons Adapted from Reference 1

\begin{tabular}{|c|c|}
\hline & Definition and explanation \\
\hline 1 & $\begin{array}{l}\text { Equal importance - two activities contribute equally to } \\
\text { the objective. }\end{array}$ \\
\hline 3 & $\begin{array}{l}\text { Moderate importance - experience and judgment slightly } \\
\text { favor one activity over another. }\end{array}$ \\
\hline 5 & $\begin{array}{l}\text { Strong importance -- experience and judgment strongly } \\
\text { favor one activity over another. }\end{array}$ \\
\hline 7 & $\begin{array}{l}\text { Demonstrated importance -- an activity is strongly } \\
\text { favored and its dominance is demonstrated in practice. }\end{array}$ \\
\hline 9 & $\begin{array}{l}\text { Extreme importance }- \text { the evidence favoring one activity } \\
\text { over another is of highest possible order of affirmation. }\end{array}$ \\
\hline $2,4,6,8$ & $\begin{array}{l}\text { Intermediate values between the two adjacent judgments -- } \\
\text { when compromise is needed. }\end{array}$ \\
\hline $\begin{array}{l}\text { Reciprocal } \\
\text { of above } \\
\text { numbers }\end{array}$ & $\begin{array}{l}\text { If an activity } i \text { has one of the above numbers assigned to } \\
\text { it when compared with activity } j \text {, then } j \text { has the reciprocal } \\
\text { value when compared with } i \text {. }\end{array}$ \\
\hline Rationals & $\begin{array}{l}\text { Ratios arising from th } \\
\text { forced by obtaining } n\end{array}$ \\
\hline
\end{tabular}

The quality of the comparison matrix depends on good judgment consistency which we can assess by using a measure (CI) of how close $\lambda_{\max }$ (the biggest eigenvalue of $A$ ). is to $n$, which is called the consistency index:

$$
C I=\left(\lambda_{\max }-N\right) /(n-I)
$$

the calculated value of CI may be compared with its average value (RI) for randomly generated reciprocal matrix of the same dimension as $A$. The value of the Random Consistency Index is given by: 
Table 2. The value of $R I$

Finally, CI and RI are compared via an index called the consistency ratio:

$$
C R=C I / R I
$$

If $\mathrm{CR}<0.10$, the consistency can be accepted, otherwise estimates must be revised if $C R$ exceeds a suggested limit of $10 \%$. Now a matrix can be set up to carry out the pairwise comparison of the relative importance and develop the priorities (weights) of the elements in the second level with respect to the destination in the first level.

Table 3. Weights of criteria

\begin{tabular}{|l|l|l|l|l|l|}
\hline$G$ & $C 1$ & $C 2$ & $C 3$ & $C 4$ & $W$ \\
\hline$C 1$ & 1 & $1 / 2$ & 5 & 8 & 0.337 \\
\hline$C 2$ & 2 & 1 & 7 & 9 & 0.535 \\
\hline$C 3$ & $1 / 5$ & $1 / 7$ & 1 & 3 & 0.086 \\
\hline$C 4$ & $1 / 8$ & $1 / 9$ & $1 / 3$ & 1 & 0.042 \\
\hline
\end{tabular}

Comparison matrices can be further set up to compare the elements of the third level and derive their weights with respect to the appropriate parents in the second level. 
Table 4. Modal comparisons

\begin{tabular}{|l|l|l|l|}
\hline$C 1$ & $F 1$ & $F 2$ & $W$ \\
\hline$F 1$ & $I$ & 6 & 0.857 \\
\hline$F 2$ & $1 / 6$ & 1 & 0.143 \\
\hline
\end{tabular}$\quad \begin{aligned} & C I=0 \\
& C R=0\end{aligned}$

\begin{tabular}{|l|l|l|l|}
\hline C2 & F3 & F4 & $W$ \\
\hline F3 & 1 & 4 & 0.8
\end{tabular}$\quad \begin{aligned} & \text { CI }=0 \\
& \text { CR }=0\end{aligned}$

\begin{tabular}{|c|c|c|c|}
\hline $\mathrm{C} 3$ & F5 & F6 & $\mathrm{W}$ \\
\hline F5 & 1 & 2 & 0.667 \\
\hline F6 & $1 / 2$ & 1 & 0.333 \\
\hline
\end{tabular}

In this paper, the values of the above-mentioned matrices are determined with the aid of investigations and consulting many experts.

The weights in the level of subcriteria are synthesized by multiplying local priorities by the priority of their corresponding criterion in the level above, and adding them for relevant elements in the level according to the criterion it affects. This gives the composite priority of elements in the level of subcriteria with respect to the destination. (See Table 5)

\section{Global estimated value of three alternatives}

The AHP has been applied to set priorities on the levels of criteria and subcriteria, the importance of each alternative with respect to each subcriterion can be measured by the concept of 
"membership degree" ( $\mu)$ quoted from Fuzzy Mathematics, and the membership degree can be calculated with the aid of membership function.

Table 5. The composite weight of subcriteria

\begin{tabular}{|c|c|c|c|c|c|c|c|}
\hline$G$ & F1 & F2 & F3 & F4 & F5 & F6 & F7 \\
\hline$C 1(0.337)$ & 0.857 & 0.143 & & & & & \\
\hline$C 2(0.535)$ & & & 0.8 & 0.2 & & & \\
\hline$C 3(0.086)$ & & & & & 0.667 & 0.333 & \\
\hline C4 (0.042) & & & & & & & 1 \\
\hline $\begin{array}{l}\text { composite } \\
\text { priority }\end{array}$ & 0.289 & 0.048 & 0.428 & 0.107 & 0.057 & 0.029 & 0.042 \\
\hline
\end{tabular}

Seven typical technical indices of locomotives are chosen corresponding with seven subcriteria respectively, those indices represent the characteristics of railway traffic, their statistical figures ( $\xi$ ) can be derived from reference 4 . They can be classified into two kinds, the first kind containing those indices for which the larger their statistical figures are, the higher their membership degrees are.

Their membership function is as follows:

$$
\begin{aligned}
& \text { If } 0 \Leftrightarrow \xi \Leftrightarrow \xi_{\min } \text { then } \mu(\xi)=0 \\
& \xi_{\min }<\xi<\xi_{\max } \quad \mu(\xi)=\left(\xi-\xi_{\min }\right) /\left(\xi_{\max }-\xi_{\min }\right) \\
& \xi>=\xi_{\max } \quad \mu(\xi)=1
\end{aligned}
$$

These indices and their dimensions are:

(FI3) : locomotive gross ton-kilometers.

(hundred milition ton-kilometers / locomotive) 
(FI4) : technical speed.

(kilometer / hour)

(FI5) : manufacturing output of Iocomotive. (Iocomotive / year)

(FI6) : number of locomotives under repair. (locomotive / year)

The second kind of indices have the opposite characteristics, i.e., the smaller their statistical figures are, the higher their membership degrees are.

The membership function is as follows:

$$
\text { If } 0<=\text { r } \begin{aligned}
0<\xi_{\min } & \text { then } \mu(\xi) & =1 \\
\xi_{\min }<\xi<\xi_{\max } & \mu(\xi) & =\left(\xi-\xi_{\min }\right) /\left(\xi_{\max }-\xi_{\min }\right) \\
\xi>=\xi_{\max } & \mu(\xi) & =0
\end{aligned}
$$

These indices and their dimensions are:

(FII) : investment in capital construction.

(FI2) : expenditure on power.

(yuan / gross ton-kilometers ten thousand)

(FI7) : consumption of standard fuel.

(kilogram / ton-kilometers ten thousand)

The membership degrees of seven indices mentioned above are given in Table 6 .

Now, seven indices which belong to different kinds and have different dimensions can be compared with the same target-membership degree, and the higher their membership degrees are, the better estimation of relevant haulage mode is. 


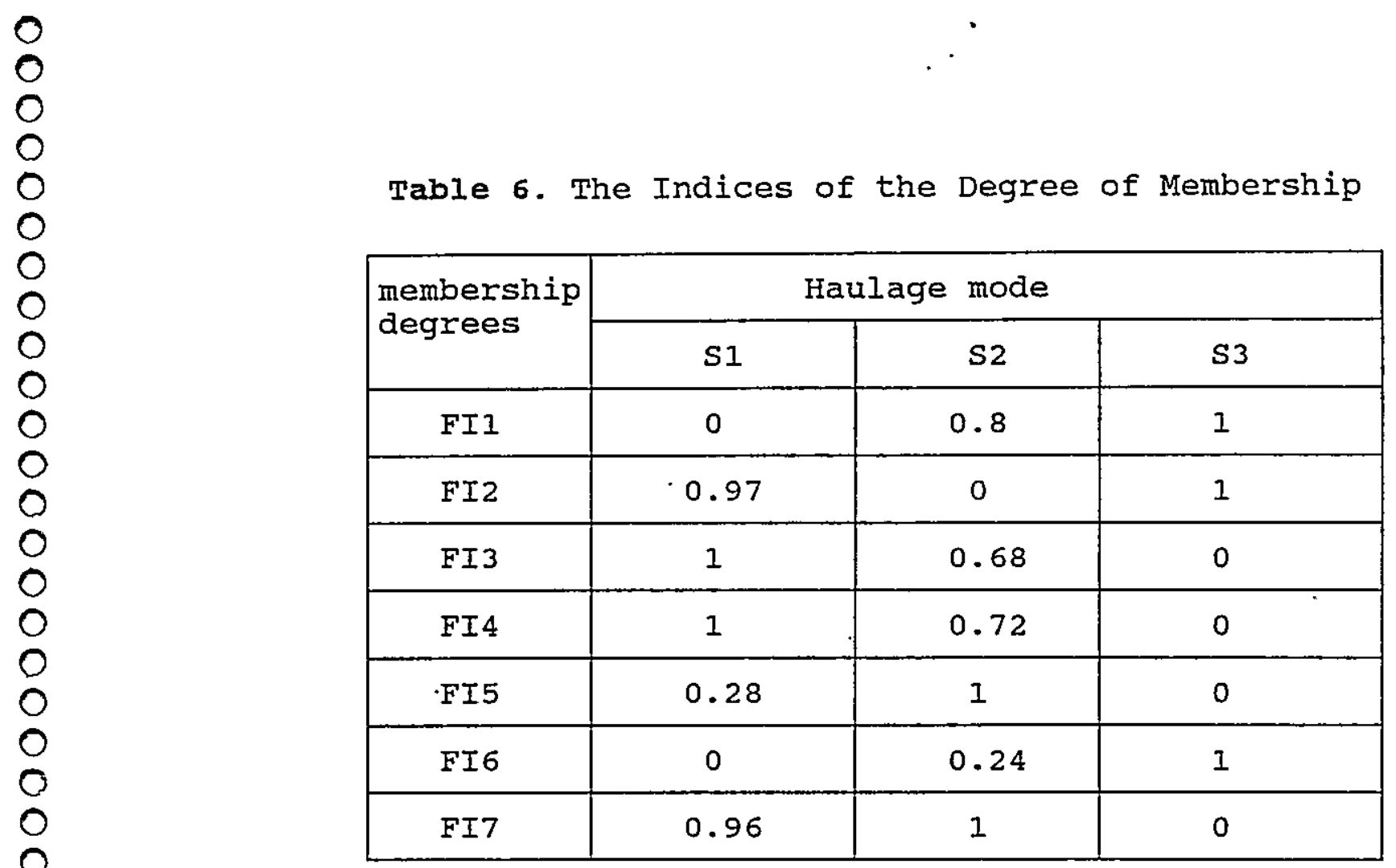

The global estimated values of three alternatives are derived using the Multi-graded Linear Weighted, Method:

Where

$$
\mathrm{R}=\mathrm{W} * \mathrm{U}
$$$$
w=[w(1), w(2), \ldots w(7)]
$$

and

$$
U=\left[\begin{array}{ccc}
\mu(1,1) & \mu(1,2) & \mu(1,3) \\
\mu(2,1) & \mu(2,2) & \mu(2,3) \\
\mu(\dddot{7}, 1) & \mu(\dddot{7}, 2) & \mu(\dddot{7}, 3)
\end{array}\right]
$$

$R$ is the vector of global estimated value, $W$ is the weight vector, $U$ is the matrix of membership degree, $\mu(i, j)$ represents the membership degree of $j$ haulage mode to be chosen with respect to $i$ index, so we can derive the global estimated values of the three alternatives. 
Table 7. The global estimated values

\begin{tabular}{|l|c|c|c|}
\hline \multirow{2}{*}{} & \multicolumn{3}{|c|}{ Haulage mode } \\
\cline { 2 - 4 } & S1 & S2 & S3 \\
\hline Value & 0.636 & 0.695 & 0.366 \\
\hline Order & 2 & 1 & 3 \\
\hline
\end{tabular}

We can get the further result with the aid of the following model:

$$
\begin{aligned}
\mathrm{R} I & =\mathrm{WI} * \mathrm{U} I \\
\mathrm{WI} & =[\mathrm{W}(\mathrm{k}), \mathrm{W}(\mathrm{k}+1), \ldots \mathrm{W}(\mathrm{m})] \\
\mathrm{U} 1= & {\left[\begin{array}{ccc}
\mu(\mathrm{k}, I) & \mu(\mathrm{k}, 2) & \mu(\mathrm{k}, 3) \\
\mu(\mathrm{k}+1,1) & \mu(\mathrm{k}+1,2) & \mu(\mathrm{k}+1,3) \\
\mu(\dot{\mathrm{m}}, 1) & \mu(\mathfrak{\mathrm { m }}, 2) & \mu(\mathfrak{\mathrm { m }}, 3)
\end{array}\right] }
\end{aligned}
$$

where $\mathrm{k}$ is the ordinal of beginning subcriterion belonging to criterion $i$; and $m$ is the ordinal of suspending subcriterion belonging to criterion $i$.

The comparative estimated value of three haulage mode with respect to four criteria can be calculated (See Table 8)

Table 8. The comparative estimated value

\begin{tabular}{|c|c|c|c|}
\hline \multirow{2}{*}{ Criteria } & \multicolumn{3}{|c|}{ Haulage mode } \\
\cline { 2 - 4 } & S1 & S2 & S3 \\
\hline CI & 0.046 & 0.231 & 0.337 \\
\hline C2 & 0.535 & 0.358 & 0 \\
\hline C3 & 0.016 & 0.064 & 0.029 \\
\hline C4 & 0.039 & 0.042 & 0 \\
\hline
\end{tabular}




\section{Analysis and Proposal}

From Table 7, the conclusion can be drawn that diesel locomotives are the optimal haulage mode by china's current national condition.

Some experts adhere to opinions that China should be in the way that many advanced countries have chosen to give priority to the development of electric locomotive, but it can be observed from Table 8 that diesel locomotives have obvious advantage in economization on funds over electric locomotives, the former's capacity of manufacturing and maintenance is better than the latter's, and diesel locomotives can economize on energy, even though electric locomotives have obvious advantage determined by its attractive characteristics in hauling capacity, so we ought not to concentrate on electrification in the near future unilaterally. our country can develop diesel locomotives and electric locomotives simultaneously and take a precedence to the former now. As time goes on, Chinese economic environment will be improved progressively, and correspondingly the manufacturing structure of locomotives should be adjusted. It is necessary for our country to throw more funds to expand the manufacturing capacity of electric locomotives and enlarge the number of kilometers that are electrified.

From Table 7 it can be noticed that the global estimated value of steam locomotives is lowest, and from Table 8 it can be noticed further that steam traction has lowest traffic capacity and its consumption of energy is highest, which are its main inferiorities, 
but as it once was the primary haulage mode, there have been higher numbers of steam locomotives so far. If our country follows the example of some advanced countries to use diesel locomotives and electric ones only and let steam locomotives lie idle, it is inevitable for the chinese railway to cause unnecessary waste of installation and aggravate tension of railway traffic, so the using scope of steam locomotives should be reduced step by step.

The further suggestion is to stop manufacturing steam locomotives, and the technique, property and manpower of steam locomotive's manufacturing plants can be transferred to produce electric locomotives.

The problem of haulage mode-choice of China's railway traffic discussed in this thesis is of important practical significance, this multicriteria problem has been inquired into tentatively in this paper. Relevant criteria can be further resolved and discussed. The relevant priorities and estimation vary in accordance with the variation of time and restrictive conditions.

The approach proposed in this paper has better flexibility, and it can be used to forecast the haulage mode-choice of future years (eg: 2000 A.D. and 2020 A.D.) with the aid of the AHP's software, Expert Choice.

\section{References}

1. T.L. Saaty, Axiomatic Foundation of the Analytic Hierąrchy Process, Management Science, Vol. 32, No. 7, July 1986.

2. Shubo Xu, The Principles of the AHP (in chinese), 


\section{0}

0

0

0

0

0

0

0

0

0

0

0

0

0

0

0

0

0

0

C

0

0

0

0

0

0

$c$

C

0

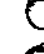

0

0

0

0

0

0

0

0

0

0

0

0

0

0

0

0

0

0

0

0

C

0
Tianjian Publishing House, China, 1986.

3. Xinxian Lie, Daoli zhu, Selection and Deduction (in chinese), Shanghai Publishing House, China, 1986.

4. Planning Department of Railway, The Handbook of Railway's Main Indices (to 1989) 